\title{
The Structures of Vanadium Oxide Cluster-Ethene Complexes. A Combined IR Multiple Photon Dissociation Spectroscopy and DFT Calculation Study
}

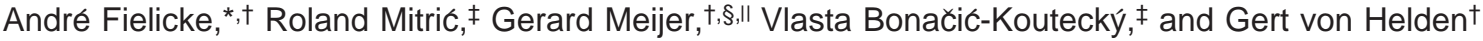 \\ FOM Institute for Plasma Physics "Rijnhuizen”, Edisonbaan 14, NL-3439 MN Nieuwegein, The Netherlands, \\ Institut für Chemie, Humboldt-Universität zu Berlin, Brook-Taylor-Strasse 2, D-12489 Berlin, Germany, Department \\ of Molecular and Laser Physics, University of Nijmegen, Toernooiveld, NL-6525 ED Nijmegen, The Netherlands, \\ and Fritz-Haber-Institut der Max-Planck-Gesellschaft, Faradayweg 4-6, D-14195 Berlin, Germany
}

Received May 21, 2003; E-mail: fielicke@rijnh.nl

Vanadium is one of the most important transition metals in supported metal oxide catalysis, where it is mainly used as an oxidation catalyst. ${ }^{1}$ However, in most of these catalytic reactions, the mechanisms on a molecular scale and the relevant active sites are still under discussion. Gas-phase vanadium oxide clusters have been suggested as model systems for active sites, and reactions with small organic molecules have been studied experimentally using mass spectrometric techniques. ${ }^{2-4}$ Evidence for oxygen transfer reactions has been found. ${ }^{2,3}$ On the basis of the structurereactivity relationship obtained from DFT calculations, a radical center mechanism has been proposed to be responsible for the sizeselective oxygen transfer. ${ }^{3}$ The complexity and importance of those reactions cause a continued interest in the mechanisms of these reactions as well as in the structures of the oxide clusterhydrocarbon complexes.

Most of the knowledge about the structure-reactivity relationships for gas-phase clusters has been gained indirectly from experimental chemical reactivity, in some cases combined with quantum chemical calculations. More direct structural information can be obtained from vibrational spectroscopy. IR multiple photon dissociation (IR-MPD) with line tunable $\mathrm{CO}_{2}$ lasers has been used to obtain IR spectral information for some metal cluster complexes in a limited spectral range around $10 \mu \mathrm{m} .{ }^{5}$ Using a free electron laser (FEL) as an intense and widely tunable IR source, IR-MPD spectra have been measured for oxide clusters of vanadium, niobium, and tantalum, ${ }^{6-8}$ as well as for some complexes of metal clusters. ${ }^{9,10}$ For some small oxide clusters, this led to structural identification through comparison with DFT calculations.

Here, we report on IR-MPD experiments that are performed in a molecular beam setup on cluster ions directly emitted by a pulsed laser vaporization cluster source that is combined with a reaction channel. An additional pulsed valve delivers the ethene to the reaction channel, where the clusters react near thermal energy. The setup is described in more detail elsewhere. ${ }^{7,10,11}$ The clusters and their complexes form a molecular beam that is overlapped collinearly with the intense infrared beam of the Free Electron Laser for Infrared eXperiments (FELIX). ${ }^{11,12}$ When the laser frequency is resonant with an IR-active vibration of a cluster, the cluster can absorb several photons and subsequently undergo fragmentation. The changes in the cationic cluster mass distribution are monitored as a function of FELIX wavelength. The mechanism of IR multiple photon absorption has been discussed recently in the context of IR resonance enhanced multiple photon ionization (IR-REMPI) spectroscopy of clusters ${ }^{11}$ as well as IR-MPD of gas-phase molecular ions. ${ }^{13}$

\footnotetext{
$\dagger$ FOM Institute for Plasma Physics.

\# Humboldt-Universität zu Berlin.

\&university of Nijmegen.

"Fritz-Haber-Institut der Max-Planck-Gesellschaft
}

The use of IR spectroscopy for structural identification depends on the ability of theoretical methods to accurately predict structural and dynamical properties as well as energetics. Therefore, the structural assignment is a joint experimental and theoretical effort. Recent work on structural properties of cationic vanadium oxide clusters and their reactivity with ethene has shown that the DFT methods, in particular, the hybrid gradient corrected functionals (B3LYP) in combination with sufficiently large basis sets of triple- $\zeta$ quality (TZVP), allow accurate determination of the structural features and also of the structure-reactivity relationship. ${ }^{3}$ Structural properties of anionic and neutral ${ }^{14}$ as well as cationic ${ }^{15} \mathrm{~V}_{x} \mathrm{O}_{y}$ have been calculated using the same procedure. These findings gave us confidence to extend this approach to the interpretation of vibrational IR spectra of cationic vanadium oxide-ethene complexes reported in this work. For this purpose, the vibrational frequencies and IR intensities have been calculated within the harmonic approximation and are compared here to experimental data.

IR-MPD spectra for the complexes of $\mathrm{V}_{2} \mathrm{O}_{5}{ }^{+}$and $\mathrm{V}_{2} \mathrm{O}_{6}{ }^{+}$with $\mathrm{C}_{2} \mathrm{H}_{4}$ are shown in Figure 1 together with the calculated spectra of some isomers. Both oxide cluster cations are open-shell systems; in $\mathrm{V}_{2} \mathrm{O}_{5}{ }^{+}$, the unpaired electron is located at a terminal $\mathrm{V}-\mathrm{O}^{\bullet}$ group, whereas $\mathrm{V}_{2} \mathrm{O}_{6}{ }^{+}$contains a superoxo group (formally $\mathrm{O}_{2}{ }^{--}$) that can be identified via its characteristic IR absorption at $\sim 1150 \mathrm{~cm}^{-1}$. Good agreement is achieved between the experimental IR spectra of $\mathrm{V}_{2} \mathrm{O}_{5} \mathrm{C}_{2} \mathrm{H}_{4}^{+}$(I) and $\mathrm{V}_{2} \mathrm{O}_{6} \mathrm{C}_{2} \mathrm{H}_{4}^{+}$(II) and the calculated spectra of the isomers Ic and IIa, respectively (Ia is incompatible due to the observed fragmentation behavior; see below). In principle, the agreement could be improved if one would introduce an optimal scaling factor for all modes involving $\mathrm{V}-\mathrm{O}$ stretches. Because of the lack of reference data for similar gas-phase molecules, we used here a rather arbitrary factor of 0.95 for all vibrational frequencies. While IIa is the lowest energy isomer of $\mathrm{V}_{2} \mathrm{O}_{6} \mathrm{C}_{2} \mathrm{H}_{4}{ }^{+}$, Ic is 1.98 $\mathrm{eV}$ higher in energy than the minimum energy isomer Ia obtained for $\mathrm{V}_{2} \mathrm{O}_{5} \mathrm{C}_{2} \mathrm{H}_{4}{ }^{+}$.

In addition to the IR spectral information, fragmentation pathways can be identified by analyzing the frequency dependence of the intensity increase of the fragment ions. For complex $\mathbf{I}$, the observed fragmentation channel is $\left[\mathrm{C}_{2} \mathrm{H}_{4}\right]$ loss, and for II loss of $\left[\mathrm{C}_{2} \mathrm{H}_{4} \mathrm{O}_{2}\right]$ (presumably successive loss of $\mathrm{C}_{2} \mathrm{H}_{4}$ and $\mathrm{O}_{2}$ ) is observed. The calculated energetics of the $\mathrm{V}_{2} \mathrm{O}_{5}{ }^{+} / \mathrm{C}_{2} \mathrm{H}_{4}$ system are shown in Figure 2. A reaction between $\mathrm{C}_{2} \mathrm{H}_{4}$ and $\mathrm{V}_{2} \mathrm{O}_{5}{ }^{+}$could follow the lowest energy path, but then the high intrinsic energy should cause immediate formation of the acetaldehyde as oxidation product. If Ia would nonetheless form for some reason, pumping it with IR light is expected to induce rearrangement to an acetaldehyde complex of $\mathrm{V}_{2} \mathrm{O}_{4}{ }^{+}$(Id), combined with loss of acetaldehyde. Neither the strong $v_{\mathrm{CO}}$ absorption of Id (at $1584 \mathrm{~cm}^{-1}$ ) nor loss of $\left[\mathrm{C}_{2} \mathrm{H}_{4} \mathrm{O}\right]$ has been experimentally observed. Although the IR spectra of Ia 

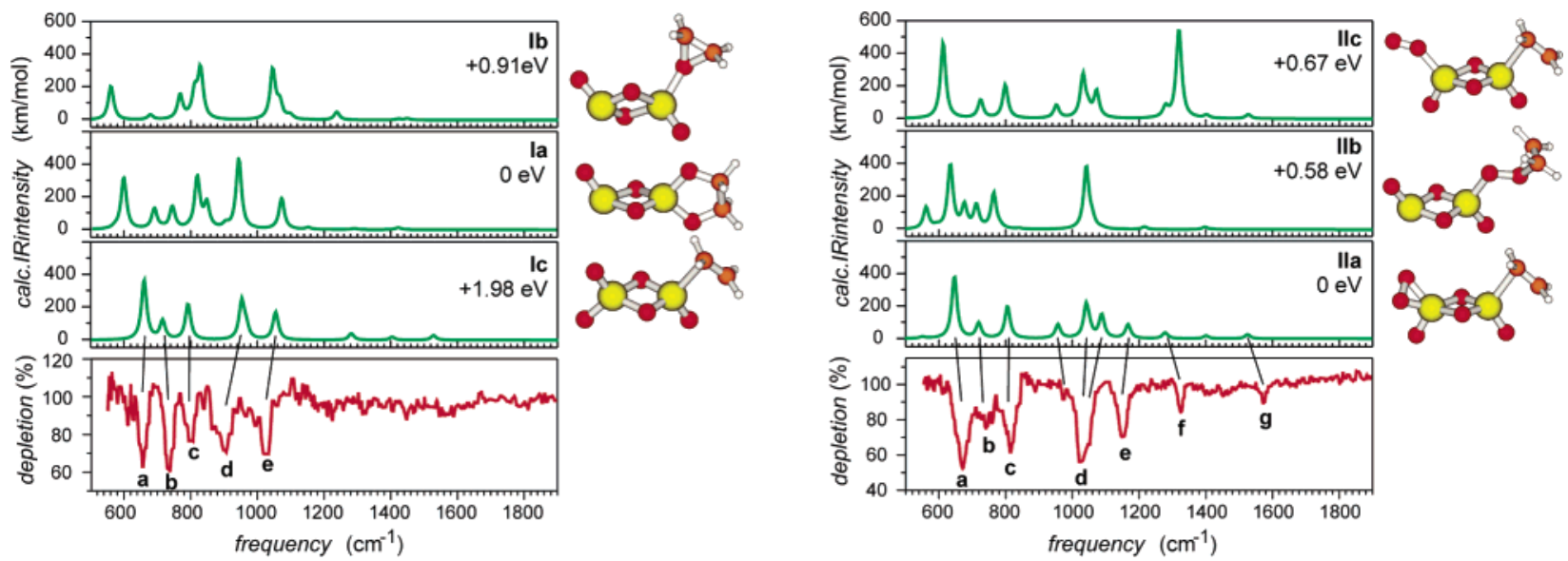

Figure 1. Infrared multiple photon dissociation (IR-MPD) spectra of $\mathrm{V}_{2} \mathrm{O}_{5} \mathrm{C}_{2} \mathrm{H}_{4}^{+}$(I) and $\mathrm{V}_{2} \mathrm{O}_{6} \mathrm{C}_{2} \mathrm{H}_{4}{ }^{+}$(II) together with calculated spectra for several isomers.

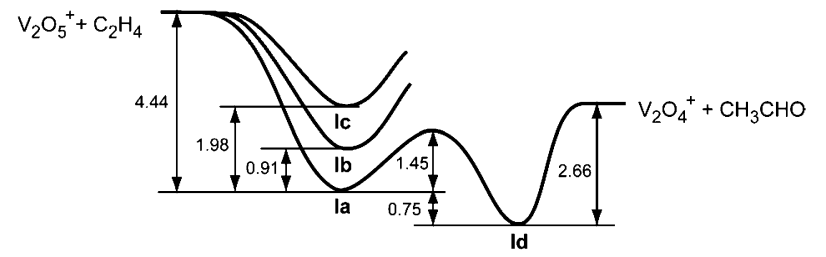

Figure 2. Schematic diagram showing the relative energies (in $\mathrm{eV}$ ) of four different isomers of $\mathrm{V}_{2} \mathrm{O}_{5} \mathrm{C}_{2} \mathrm{H}_{4}{ }^{+}(\mathbf{I a}-\mathbf{d})$ and the energetics of the ethene oxidation on Ia leading to acetaldehyde (compare ref 3).

and Ic are similar, the observed loss of $\left[\mathrm{C}_{2} \mathrm{H}_{4}\right]$ thus makes the presence of Ic more probable, and, instead of forming the energetically more stable $\mathrm{O}-\mathrm{C}$ bonds, the ethene subunit seems to be bound directly to the vanadium atom with the lowest $\mathrm{O}$ coordination in both Ic and IIa.

From these findings, the question arises of why the vanadium oxide clusters behave differently during reaction with ethene in our experiment than at the conditions of mass selected cluster reactivity measurement. There, ${ }^{3}$ theory predicts the bonding of ethene to an $\mathrm{O}$-site as the initial step for the experimentally observed reduction of $\mathrm{V}_{2} \mathrm{O}_{5}{ }^{+}$. However, we find the ethene to bind to a V-site. We suggest that this is caused by the influence of an electrostatic effect on the geometry of the ion molecule reaction. The positive charge is located in the oxide cluster at the lowest coordinated $\mathrm{V}$-atom and can orient the ethene molecule. In that way, an intermediate ion-molecule complex is formed which is not necessarily the lowest energy structure. Thus, the here identified structures resemble the primary collision complexes that are formed at thermal collision energies. In a mass selected cluster reactivity measurement, the collision energies are typically at least a few electronvolts. Even if this energy is only partly transferred into internal energy, barriers can be overcome, and more stable products can be formed.

The comparison of the experimental and calculated spectra as well as (qualitative) investigations of the laser power dependence of the dissociation spectra gave us no evidence for the presence of different structural isomers of I or II. For II, the calculated IR spectra of the higher energetic isomers differ more from the experimental spectrum than for the most stable isomer, thus supporting the assignment to IIa. For I, the observed loss of $\left[\mathrm{C}_{2} \mathrm{H}_{4}\right]$ complements the ambiguous spectroscopic observations, giving evidence for the presence of isomer Ic. In both complexes, the ethylene molecule binds to the initially positively charged $\mathrm{V}$ atom.

In conclusion, we have presented infrared spectra of complexes of transition metal oxide clusters with a hydrocarbon molecule. We conclude that the cationic nature of the vanadium oxide clusters may have a dominating influence over the reactions under the applied conditions.

Acknowledgment. We gratefully acknowledge financial support by the Stichting voor Fundamenteel Onderzoek der Materie (FOM) and the EU IHP Research Training Network (Delayed Ionization and Competing Cooling Mechanisms in Atomic Clusters). A.F. thanks the Deutsche Forschungsgemeinschaft for a fellowship.

Supporting Information Available: Structures, vibrational frequencies, and IR intensities for $\mathbf{I a}-\mathbf{d}$ and $\mathbf{I I a}-\mathbf{c}$, and band assignments for I and II (PDF). This material is available free of charge via the Internet at http://pubs.acs.org.

\section{References}

(1) Weckhuysen, B. M.; Keller, D. E. Catal. Today 2003, 78, 25.

(2) Zemski, K. A.; Justes, D. R.; Castleman, A. W., Jr. J. Phys. Chem. B 2002, 106, 6136. Bell, R. C.; Castleman, A. W., Jr. J. Phys. Chem. A 2002, 106, 9893

(3) Justes, D. R.; Mitrić, R.; Moore, N. A.; Bonačić-Koutecký, V.; Castleman, A. W., Jr. J. Am. Chem. Soc. 2003, 125, 6289.

(4) Fielicke, A.; Rademann, K. Phys. Chem. Chem. Phys. 2002, 4, 2621. Dinca, A.; Davis, T. P.; Fisher, K. J.; Smith, D. R.; Willett, G. D. Int. J. Mass Spectrom. 1999, 182/183, 73.

(5) Zakin, M. R.; Brickman, R. O.; Cox, D. M.; Reichmann, K. C.; Trevor, D. J.; Kaldor, A. J. Chem. Phys. 1986, 85, 1198. Knickelbein, M. B. Annu. Rev. Phys. Chem. 1999, 50, 79. Koretsky, G. M.; Knickelbein, M. B.; Rousseau, R.; Marx, D. J. Phys. Chem. A 2001, 105, 11197. Dietrich, G.; Krückeberg, S.; Lützenkirchen, K.; Schweikhard, L.; Walther, C. J. Chem. Phys. 2000, 112, 752 .

(6) Asmis, K. R.; Brümmer, M.; Kaposta, C.; Santambrogio, G.; von Helden, G.; Meijer, G.; Rademann, K.; Wöste, L. Phys. Chem. Chem. Phys. 2002, 4, 1101. Fielicke, A.; Meijer, G.; von Helden, G. Eur. Phys. J. D 2003, $24,69$.

(7) Fielicke, A.; Meijer, G.; von Helden, G. J. Am. Chem. Soc. 2003, 125, 3659 .

(8) Asmis, K. R. 2002, private communication. IR spectra of $\mathrm{V}_{2} \mathrm{O}_{x}^{+}(x=$ $2-6)$ were reported at ISSPIC 11 in Strasbourg, France, September 2002.

(9) Simard, B.; Dénommée, S.; Rayner, D. M.; van Heijnsbergen, D.; Meijer, G.; von Helden, G. Chem. Phys. Lett. 2002, 357, 195.

(10) Fielicke, A.; von Helden, G.; Meijer, G.; Simard, B.; Dénommée, S.; Rayner, D. M. J. Am. Chem. Soc. 2003, 125, 11184

(11) von Helden, G.; van Heijnsbergen, D.; Meijer, G. J. Phys. Chem. A 2003 107, 1671.

(12) Oepts, D.; van der Meer, A. F. G.; van Amersfoort, P. W. Infrared Phys. Technol. 1995, 36, 297.

(13) Oomens, J.; Tielens, A. G. G. M.; Sartakov, B.; von Helden, G.; Meijer, G. Astrophys. J. 2003, 591, 968.

(14) Vyboishchikov, S. F.; Sauer, J. J. Phys. Chem. A 2000, 104, 10913 Vyboishchikov, S. F.; Sauer, J. J. Phys. Chem. A 2001, 105, 8588.

(15) Sauer, J.; Vyboishchikov, S. F. Poster presentation, Humboldt-Universität zu Berlin, Germany, February 2002

JA036264D 